\title{
A proposal to rescue rationality in Brazilian design education
}

Regardless its undeniable universal dimension as an intrinsic activity of man, there is no way to deny that design understanding is something culturally situated. In some sense, its understanding suffers direct interference from the original circumstances of each cultural environment. Every culture has its own instruments and habits to develop its projects. Although, given the almost synchronous planetary technology, one can admit a quite common nature to some proper current objects of contemporary life.

So, it seems to be a paradox to face here. Which way should we, design educators, trail? Should we call for reason, with its universal approach, whenever facing such similar complex problems throughout the world?

This article intents to observe this kind of relations while considering design education in Brazil. Besides its widespread today, Brazilian design is still very far from achieving the purpose that should be its core issue - to improve a proper approach to the serious design problems that reach all segments of Brazilian society .

keywords design culture, national identity, design theory, design education, Brazil

\section{Introduction}

Within the professional field, design understanding is very dynamic, always expanding itself and very often permeated by a series of misconceptions, mostly referring to its relation to Brazilian social dynamics. To common sense, it is socially widespread in Brazil a design conception almost exclusively associated with aesthetic interventions and artistic practice. Therefore, so unlike the Anglo-Saxon origin of the activity since the 17th century' which gives it a much broader bias by proposing design as projective action associated with all fields of human activity. Thus, in Brazil, the prospect of widening these universe of relations with the whole of the society remains restricted.

Embedded into this misunderstanding it is a problem pointed out by Brazilian historian Sergio Buarque de Holanda in his metaphor of "the seeder and the tiler" in which, while comparing Spanish and Portuguese colonizing experiences, the second one features as having a certain laissez-faire, a certain kind of being without prior planning, no future project unless the immediate (Buarque de Holanda, 2000: 1002).

\footnotetext{
'According to Oxford dictionaries, the word had its origin even earlier, in the late Middle English period (14th and 15th centuries), with the same broadness and meaning of today.

${ }^{2}$ Most renowned Brazilian historian, Sergio Buarque de Holanda was one of the interpreters of modern Brazil and celebrated author of Roots of Brazil, first published in 1936.
} 
This article is a first approach to map some aspects concerning the highly known Brazilian difficulty with the very notion of planning and designing.

Therefore, the city is our scenery and it must be understood as a reflection of decisions associated to acts of will, in most cases directed at answering questions partially committed to either one or another implicit or explicit intention in detriment to other values, possibly so important as the firsts.

To get along with this overview, some questions must be listed. How the artifacts that surround us come into life? How the visuality of the environment in which we live was conceived? Which are the references used throughout this huge construction process which is not naturally given, as some might think. Who are the characters and also the ideas that may have played some kind of meaningful action in preparing our material culture? All this makes the playing field of design, whose story, factors and relationships intertwine in a fabric of irregular pattern with the history, the factors and relationships that have its place within the urban space. ${ }^{3}$

We are used to stroll around very often disconnected to the complexity of meanings woven into the tangle of languages that characterize the urban environment. The multiple voices in the city, with its texts and subtexts which outlines each other through a process both polyphonic as polysemic, plot urban languages subjected to mixed interpretation and offer us an extensive field of study about the competencies and skills involved in their elaboration.

The main pursuit of the questioning started here is: how do Brazilian society understand the deepest meaning of such high complexity and how it can manage it by design? If we can accept that urban complexity, besides its geographical particularities, has gained an universal status, similarly I must begin, as a critic, both from the universal and the particular - from the universal contained in the idea of rationality, from the particular contained in the notion of culture.

This is a first try to insuflate a new spirit into Brazilian design education, one more engaged with the so complex problems to be managed inside our cities.

\section{Approaching design concepts}

Modernist imaginary, with its willingness to overcome circumstantial and chronological time, always sought an ideal tracing of a city. Its reference - the Enlightenment city as seen by Brazilian philosopher Sergio Paulo Rouanet (1999) - is the inductor space for individual autonomy covenant with the notion of a collective.

The modernist approach ${ }^{4}$ involved design activity in such a manner that for some time

\footnotetext{
${ }^{3}$ The word fabric is used here as an addition to the notion of urban fabric such as Lefebvre conceives: "The urban fabric can be described using the concept of ecosystem, coherent unit formed around one or more cities, old or new. (...) In the economic basis of the urban fabric, phenomena from a different order appear, on another level, the ones of social and cultural life. (...) Such way of living involves objects and values systems. The best known among the elements of urban system of objects are water, electricity, gas, which do not fail to be followed by cars, televisions, plastic utensils, the "modern" furniture, and that contains new requirements in regards to the 'services". (Lefebvre, 2001: 11) ${ }_{4}^{4}$ refer more specifically to the special relation maintained between morality, simplicity and universal formalism, developed since the late 19th century, which would achieve its best expression in the twenties high Modernism (Williams, 1983).
} 
it was much characterized as a defined aesthetic movement. Considered as the only acceptable design approach, overlaying other possible ways of designing, modernist design meant adherence to that particular highly structured formal code, totally adverse to criticism.

This ontological aspect proved to be much stronger among Brazilians, since the systematic implementation of design education in the country was uncritically made through the transposition of Ulm's school - Hochschule für Gestaltung - to the very specífic characteristics of Brazilian culture.

It must seem paradoxical, and it really was. I refer to the much publicized evaluation that Brazil does not belong to Western culture tradition, basically for not privileging the cult of reason. Using Ulm's model had a motive. Unlike other circumstances, where design evolved from earlier forms of craftsmanship - Finland, Italy, even Germany and England are good examples of that kind of process - the creation of the first Brazilian design school was more linked to art practice, more exactly to the advent of Concrete Art in Brazil. So, Brazilian design education was launched under two different concepts Concrete Art and the very rational way to design descending from Ulm's school.

But Its reflection upon the country's reality was as minimum as one can observe upon the recurrent problems in a huge variety of design problems. In one hand, the impossility to deal with the ideal dream of modernism. In the other one, an inability to address more complex design problems. Since design education spreaded right under modernism criticism in the seventies, no debate was put into methodological issues. As a result. it ocurred a rather low impact of design into Brazilian culture.

Since design spans over so many domains, the methodological issue of this study seems to be finding the better way to imbricate a set of well articulated and relevant understanding of Brazilian problems with a bias on the specific knowledge of design, both in its theoretical and political dimension. ${ }^{5}$ If this goal can be reached, elements for a new approach to design education in Brazil will certainly turn out to be more visible, transforming it in a truly transdisciplinary perspective - a transdisciplinary attitude and process, one linked to another, involving a crossing knowledge and its combination at the same time while seeking some kind of synthesis.

Thus, there is a need for a detailed understanding of what is meant here: design shall be understood in its complex, functional and aesthetic dimension, simultaneously. To understand and lead this kind of project, the designer must exercise a comprehensive rationality. This can be seen as a research process which deals at the same time with both an a priori judgment and an open mindset to what is offered by actual circumstances. Today, at the completion of any project, the designer is faced to a complex array of factors that carry different meanings, translated into different voices and discourses, sometimes parallel, sometimes contradictory. The need for identification of these multiple voices and aspects is valid for any project situation. So, one can say that there is a radical and intrinsic potential complexity as a structure to any project situation. To develop a design one must proceed a constant deducing and inducing questioning, and to deliver this there is a need to processing the very basic thinking tools - logic, in a broad sense. 


\section{The role of rationality in design processes}

If we consider human action and social life to be coincident, all human achievement may be seen as result of some kind of project, and so we can also consider that this extraordinary event multiplicity requires complex looks. One could assume the first task concerning the subject of a project - be it an individual governed by some kind of habit ${ }^{6}$ (Elias 1993) or a designer with his professional identity - to be to identify, to organize and systematize all those aspects and voices. However, one has to consider a possible assymmetry in those equations, which do not systematize all values involved in such situations and distribute different relevances as intended by other kind of framings.

So, it is possible to assume design as a metaphor. In different contexts, this word acquires the most varied meanings, making prevail, as its constituent elements, certain factors upon others, and vice versa. Understood as vital to the achievement of something to exist in the future, a project action is always anchored in some kind of intentionality. Ultimately design involves planning and defining something future oriented. According to Gui Bonsiepe, this is a basic characteristics of any action undertaken by design, which he defined as "a domain that can be manifest in any area of human knowledge and praxis" (Bonsiepe 1989). For designing both reveals a concept that is not limited to a specific territory of action and, in a sense, tends to a certain abstraction due to the variability of its object. Thus, to project may not be automatically confused with a design action although it must present itself as its essential characteristic.

On designing, a project action involves a comprehensive settlement of the problem to be faced. Designing, whatever may be the exact expertise involved, means to construct a problem in multiple links concerning its meaning, aspects of production, related use aspects, the impact on the environment, among many other possibilities.

If free ideas association devoid of the tension caused by a rational ordination of thought can present itself as a raw material for ideation processes, it is deductible that design somehow implies a kind of thinking that seeks its goal without proposing a linear and deductive way of reason. This reinforces the idea of intuition as an innovative competence (Bonsiepe 1997) and it does not correspond to an exclusively rationalized action but incorporates other possibilities of reality aprehension and therefore of action upon it. Just as there are different types of projective action, there are different ways to design in design. The purpose of realization of something is the only true dimension resulting from design action as an integrative thinking process.

This implies exercising elementary operations of thought: to identify, to categorize, collate, analyze, to submit to criticism. These operations are not necessarily intrinsic to all men and cultures. Different culture systems operate with distinguished modes one from another. Among Brazilians, for example, prevails an operation much ordered by affection or by an intuition not necessarily permeated by rationality. There is a kind of a national belief in its own creativity or its intrinsic capacity to solve things by improvisation. And this notion impacts very deeply the whole of design education practice.

Therefore we must confront the appropriateness of an universal concept of design in face to so diverse circumstances. There is no way to adopt a general principle if we start from a level where differentiation is the norm. However, when confronting such complex

\footnotetext{
${ }^{6}$ In the first volume of his The Civilizing Process, "A history of manners", Elias weaves a long digression on the relationship between habit and behaviour.
} 
relationships, we need improved inquisitive eyes, and maybe we must admit an imperative need of thought in the strictest sense as established in Western antiquity.

If the one who designs does not interlink some thinking operations, all that remains is a kind of an erratic process of ideation, even without guessing, because even that pressuposes a way of establishing cause and effect connections. Aristotle's notion of forethought brought into scene by Buchanan (Buchanan, 1995) refers to that "architectonic' or 'master art" concerning any kind of project and planning.

\section{Conclusion}

Is it possible to make this theme the focus of a questioning? I believe so, and the relation established in Western imaginary between civilizing process and a certain predisposition to design and planning undoubtedly plays here an important role. On the other hand, if one can imbricate social development, wealth and design, the latter accepted as decorrent from the first ones, to address projective attitudes toward complexity and functionality are impositive.

Which are the causes of such a difficulty in devising comprehensively design actions relating to the human habitat in Brazil ? Asking that leads us to propose a not very much practiced interaction in order to shape design as a social practice in Brazil.

Among designers most interested to approach the world through their senses, reason emerges as an actual analysis perspective, differentiation, collation and decision, fundamental to exercise thinking tools, be it associated or not to other key instruments as imagination, for instance. Complex problems cannot be addressed under the sign of selfexpression or hedonism. There will be a need for rationality.

The very notion of project - as a verb, as a noun - is something intrinsic to an elaborated culture. It is something more likely a rationale put in the service of social and individual intentions. To exalt project as an indicator of civilization means to advance over time, modelling possible solutions, enabling the testing and evaluation of impacts, of future aspects and unforeseen events. To explore creativity in a rational way, through both deduction and induction, means, in Brazilian terms, to appropriate the much celebrated Brazilian creative potential while, in parallel, to incorporate consistent diagnosis and evaluation procedures.

Reason, as pointed out by Dorothea Frede and James Wang (Wang 2013), is one of the key elements to assess future actions and their consequences. According to them, by connecting imagination and reason, this is what establishes a sense of the human.

\section{References}

Bonsiepe, Gui. (1989) Paper presented at a meeting sponsored by Laboratorio Brasileiro de Design, Santa Catarina.

-------. (1997) Design: do material ao digital. Florianopolis, BR: CTAI/LBDI Laboratório Brasileiro de Design

Buarque de Holanda, Sérgio. (2000) "Raízes do Brasil". In Intérpretes do Brasil, Volume III. Rio de Janeiro: Nova Aguilar. [1936]

Buchanan, Richard. (1995) "Rhetoric, humanism and design" In Buchanan, Richard and Margolin, Victor (eds.) Discovering design, pp. 23-66. Chicago: University of Chicago Press. Elias, Norbert. (1993) O processo civilizador [The Civilizing Process] (two volumes). Rio de Janeiro: Jorge Zahar. [1939] 
theme 3

identity strand 2

localities / globalities

Léfèbvre, Henry. (2001) [1968] O direito à cidade. São Paulo: Centauro.

Rouanet, Sergio Paulo. (1999) "A cidade iluminista". In: Schiavo, Cléia e Zettel, Jaime.

Memória, Cidade e Cultura. Rio de Janeiro: EdUerj.

Thackara, John. (1989) Design after modernism: Beyond the object. London: Thames and Hudson.

Wang, James. (2013) "The importance of Aristotle to design thinking". In Design Issues: History, Theory, Criticism: Volume 29, Number 2. Cambridge, Ma: The MIT Press.

Williams, Raymond. (1983) Culture and Society 1780-1950. New York: Columbia University Press. [1958] 